\title{
Study of Fracture Properties of Cement Stabilized Macadam
}

\author{
Yinpeng Zhang \\ Zhengzhou Municipal Engineering Design \& Research Institute, Zhengzhou 450052, China
}

\begin{abstract}
By means of three-point bending method, the fracture toughness and fracture energy of cement stabilized macadam were measured respectively. The test results indicate that, with the increase of curing period, the fracture toughness and the fracture energy are increasing gradually. As the increase of cement content, the peak vertical load and fracture toughness of the specimen is increasing gradually, however, the fracture energy is decreasing gradually.
\end{abstract}

Keywords: Cement stabilized macadam, Fracture toughness, Fracture energy

\section{Introduction}

Compared with other semi-rigid base layer materials, cement stabilized macadam has much more advantages, such as higher strength and rigidity, and more excellent wholeness and water stability. Therefore, this material has been widely used as a kind of semi-rigid base layer material in pavement structure applications for a long period in China (Sun, 2006). However, this material also presents some disadvantages such as high brittleness, poor resistance to deformation and high shrinkage rate, and so on, so it is prone to crack when it is subjected to changes of temperature and humidity. With the existence of cracks in cement stabilized macadam base layer, reflective cracks will come into being in the asphalt surface layers, and then the service performance of the pavement is badly affected. This is one of the primary reasons for the early damage of asphalt pavement in high-grade highways.

The concept of fracture toughness $\left(K_{\mathrm{IC}}\right)$ is cited from metal fracture mechanics. The value of fracture toughness represents the ability of the material to prevent crack spreading (Myriounis, Hasan, and Barkoula, 2009). Fracture toughness is an index to describe the fracture destruction of cement stabilized macadam and it is an important criterion in analyzing the fracture properties of cement stabilized macadam. Fracture energy $\left(G_{\mathrm{F}}\right)$ is a parameter to describe the resistance on crack spreading of the material, which is the needed energy consumed by the crack to spread over unit area (Kazemi, Fazileh and Ebrahiminezhad, 2007). The value of fracture energy is close correlative with the fracture process, and it reflects the difficulty degree of crack spreading. At present, there is little information available in literature about the fracture properties of cement stabilized macadam. In this study, we conducted this experimental study and measured the fracture toughness and the fracture energy of cement stabilized macadam to reveal the effect of curing period and cement content on the fracture properties of cement stabilized macadam.

\section{Materials and Experimental Methods}

\subsection{Materials used}

Class 42.5R Ordinary Portland cement was used in this study. Four cement contents were adopted (4\%, 5\%, 6\% and 7\%). The water to be mixed was local tap water. The macadam used was composed of five kinds of aggregates with different size ranges. The aggregate has a maximum size of $30 \mathrm{~mm}$, and the aggregate with a minimum size of $2.5 \mathrm{~mm}$ was replaced by river sands. The fineness modulus of the river sands is 2.73 . The composite gradation of the aggregate referred to the median of the gradation range prescribed for cement stabilized base course materials of high-grade highway in the Chinese standard (JTJ 014-97, 2001).

\subsection{Preparation of specimens}

A series of beam specimens with the size of $100 \times 100 \times 515 \mathrm{~mm}$ were used to determine the fracture toughness and the fracture energy. The beam moulds for the preparation of beam specimens were self-made steel moulds, which were designed referring to the preparing principle of cylinder specimens in the Chinese Standard (JTJ 057-94, 2004). All the specimens were prepared by compacting at their respective maximum dry density and optimum moisture content, and the compacting and stripping of the specimens were both carried out by pressure testing machine. Before being stripped, the specimens were covered by plastic sheets and allowed to stand for 4-5 h. After stripping, the specimens sealed in plastic sheets were cured at $100 \%$ relative humidity and controlled 
temperature $\left(21 \pm 2{ }^{\circ} \mathrm{C}\right)$ before testing. In order to compare the effect of polypropylene fiber, besides the four sets of specimens of polypropylene fiber cement-stabilized macadam, another set of specimens without mixed fibers was prepared.

\subsection{Experimental Method}

In this study, the fracture parameters were measured used the three-point bending beam method. The experiment was carried out on a hydraulic pressure testing machine. The measure range of the load transducer is $0-30 \mathrm{kN}$. If the rigidity of the testing machine is too low, the elastic deformation energy cumulated inside the testing machine will be released to the specimen when the specimen cracks, and then, the specimen will fracture immediately and the whole curve of fracture can't be obtained. Therefore, in order to improve the rigidity of the testing machine and reduce the errors caused by the testing machine's lack of rigidity, four high rigidity springs were furnished around the specimen. Steel rolls and billets were furnished at the support abutment in order to reduce friction. The experimental loading and measurement device can be seen in Fig. 1.

The deflection in span centre of the beam specimen was measured using an electronic dial indicator. The electronic dial indicator was fixed on one side of the specimen by an angle bracket. A small piece of glass sheet was stuck on the underside of the specimen in the middle place. The measure head of the electronic dial indicator was tipped onto the glass sheet. The height of the two supports and the space between the two supports were adjusted in advance. After the preparation work was finished, the beam specimen was placed carefully on the two supports. After the load transducer was placed on the specimen, the position of the specimen should be adjusted to make the measure head of the electronic dial indicator, the supporting pad on the specimen, the load transducer, the supporting pad on the load transducer, the center of the upper pressure plate and the precast crack in the same vertical line. A continual and consistent loading method was adopted, and the rate of loading was reduced properly when approaching failure. During the course of testing, the relational curve of the vertical load and the deflection in span centre was measured by X-Y dynamic function recorder.

\section{Experimental results and discussion}

\subsection{Calculation of fracture toughness and fracture energy}

With the peak vertical load of the three-point bending beam specimen measured, the fracture toughness of cement stabilized macadam can be calculated as follows:

$$
K_{\mathrm{IC}}=\frac{\left(P_{V \max }+G\right) L}{4 B H^{\frac{3}{2}}} f\left(\frac{a}{H}\right)
$$

where, $K_{\mathrm{IC}}$, fracture toughness, $\mathrm{kN} / \mathrm{m}^{3 / 2} ; P_{V \max }$, peak vertical load, $\mathrm{kN} ; G$, additive weight of the loading facilities (in this study, $G=0.032 \mathrm{kN}$ ); $H$, height of the beam specimen, m; $B$, width of the beam specimen, $\mathrm{m} ; L$, span length, $\mathrm{m} ; a$, depth of the precast crack, m. $f\left(\frac{a}{H}\right)$ is a function relevant to $\frac{a}{H}$, the expression of which is as follows:

$$
f\left(\frac{a}{H}\right)=2.9\left(\frac{a}{H}\right)^{\frac{1}{2}}-4.6\left(\frac{a}{H}\right)^{\frac{3}{2}}+21.8\left(\frac{a}{H}\right)^{\frac{5}{2}}-37.6\left(\frac{a}{H}\right)^{\frac{7}{2}}+38.7\left(\frac{a}{H}\right)^{\frac{9}{2}}
$$

With the ultimate deflection in span centre and the relational curve of $P_{V}-\delta$ of the three-point bending beam specimen measured, the fracture energy of cement stabilized macadam can be calculated as follows:

$$
\begin{aligned}
& G_{F}=\frac{1}{A_{\text {lig }}}\left[W_{0}+\left(m_{1}+m_{2}\right) g \delta_{\text {max }}\right] \\
& A_{\text {lig }}=B(H-a)
\end{aligned}
$$

where, $G_{F}$, fracture energy, $\mathrm{N} / \mathrm{m} ; A_{\text {lig }}$, area of the fracture ligament of the specimen, $\mathrm{m}^{2} ; H$, height of the beam specimen, $\mathrm{m} ; B$, width of the beam specimen, $\mathrm{m} ; a$, depth of the precast crack, $\mathrm{m} ; g$, gravitational acceleration $\left(g=9.8 \mathrm{~m} / \mathrm{s}^{2}\right) ; m_{1}$, weight of the specimen between the two supports, $\mathrm{kg} ; m_{2}$, additive weight of the loading facilities (in this study, $m_{2}=3.25 \mathrm{~kg}$ ); $\delta_{\max }$, ultimate deflection in span centre of the beam specimen, 
$\mathrm{m} ; W_{0}$, area under the relational curve of $P_{V}-\delta, N \cdot m$.

\subsection{Effect of curing period on fracture toughness}

Fig. 2 shows the varying rule of the fracture toughness of the three-point bending beam specimen of cement stabilized macadam as the specimen curing period varies. From the figure, it can be seen that there is a tendency of increase in the fracture toughness with the increase of curing period. Before the specimen curing period reaches $28 \mathrm{~d}$, the increasing speed of the fracture toughness is much higher. However, with the curing period keeps on increasing, the increasing speed of the fracture toughness becomes lower. According to the former research findings, it can be found that this varying rule is similar to that of the compressive strength of cement stabilized macadam with the specimen curing period increasing. The fracture of cement stabilized macadam depends on the relative strength of cement paste and aggregate, and the strength of the binding interface between them two. On the early days of curing, the hydration reaction speed of the cement inside the matrix is so high that the cracks in cement stabilized macadam have ability to cicatrize themselves, and the earlier open cracks become closed. Therefore the ability of cement stabilized macadam to resist crack generating, crack spreading and fracture of the matrix increases quickly. However, on the later days of curing, the hydration reaction speed of the cement inside the matrix is very low, and the hydration reaction is moving into the depth of the cement binding matrix, which has good action on strength increase, whereas has no distinct effect on crack closing. Therefore the increase of the fracture toughness is becoming slowly.

\subsection{Effect of curing period on fracture energy}

Fig. 3 shows the varying rule of the fracture energy of the three-point bending beam specimen of cement stabilized macadam as the specimen curing period varies. From the figure, it can be seen that there is also a tendency of increase in the fracture energy with the increase of curing period. When the curing period of the specimen is under $60 \mathrm{~d}$, the increase speed of the fracture energy is very high. For example, the fracture energy of $60 \mathrm{~d}$ increases by $50 \%$ than that of $14 \mathrm{~d}$. While after the curing period exceeds $60 \mathrm{~d}$, the increase speed of the fracture energy becomes much lower. For example, the fracture energy of $90 \mathrm{~d}$ only increases by $8 \%$ than that of $60 \mathrm{~d}$. From before-mentioned varying rule of fracture toughness, it can be found that fracture energy and fracture toughness has the similar varying rule with the curing period varies. Accordingly, the fracture property of cement stabilized is improving with the curing period increasing no matter fracture toughness or fracture energy is the appropriate evaluation index of fracture properties of cement stabilized macadam.

\subsection{Effect of cement content on fracture toughness}

Fig. 4 shows the varying rule of the fracture toughness of the three-point bending beam specimen of cement stabilized macadam with the varying of cement content. As can be seen from the figure, the effect of cement content on the fracture toughness is great. The fracture toughness of cement stabilized macadam is increased from $67.36 \mathrm{kN} / \mathrm{m}^{3 / 2}$ to $132.87 \mathrm{kN} / \mathrm{m}^{3 / 2}$ as the cement content is increased from $4 \%$ to $7 \%$.

\subsection{Effect of cement content on fracture energy}

Fig. 5 shows the varying rule of the fracture energy of the three-point bending beam specimen of cement stabilized macadam with the varying of cement content. As can be seen from the figure, the effect of cement content on the fracture energy is also great. But the vary rule of the fracture energy is contrary to that of the fracture toughness. The fracture energy is decreasing gradually with the increase of cement content. The fracture energy of cement stabilized macadam is decreased from $192.34 \mathrm{~N} / \mathrm{m}$ to $131.12 \mathrm{~N} / \mathrm{m}$ as the cement content is increased from $4 \%$ to $7 \%$.

\section{Conclusion}

This paper reported experimental results of fracture properties study conducted on cement stabilized macadam. The following conclusions can be drawn from the results presented in this paper:

1) The curing period of the specimen has great influence on the fracture parameters of cement stabilized macadam. The fracture toughness and fracture energy have the same increasing rule as the strength. With the increase of curing period, the fracture toughness and fracture energy is increasing gradually, and the peak vertical load and the ultimate deflection in span centre of the beam specimen also have a tendency to increase gradually.

2) The cement content has great influence not only on the fracture toughness but also on the fracture energy of cement stabilized macadam. With the increase of cement content, the fracture toughness and the peak vertical load are increasing gradually, but the fracture energy is decreasing gradually. 


\section{References}

JTJ 014-97. (2001). Specifications for design of highway asphalt pavement. Beijing: China Communications Press, 2001.

JTJ 057-94. (2004). Test methods of materials stabilized with inorganic binders for highway engineering. Beijing: China Communications Press, 2004.

Kazemi, M. T., Fazileh. F. and Ebrahiminezhad, M. A. (2007). Cohesive crack model and fracture energy of steel-fiber-reinforced-concrete notched cylindrical specimens. Journal of Materials in Civil Engineering, 2007, 19(10): 884-890.

Myriounis, D. P., Hasan, S. I. and Barkoula, N. M. et al. (2009). Effects of heat treatment on microstructure and the fracture toughness of SiCp/AI alloy metal matrix composites. Journal of Advanced Materials, 2009, 41(3): $18-22$.

Sun, Z. H. (2006). Aggregate gradation optimum design of cement stabilized macadam. Journal of Building Materials, 2006, 9(6): 675-680.

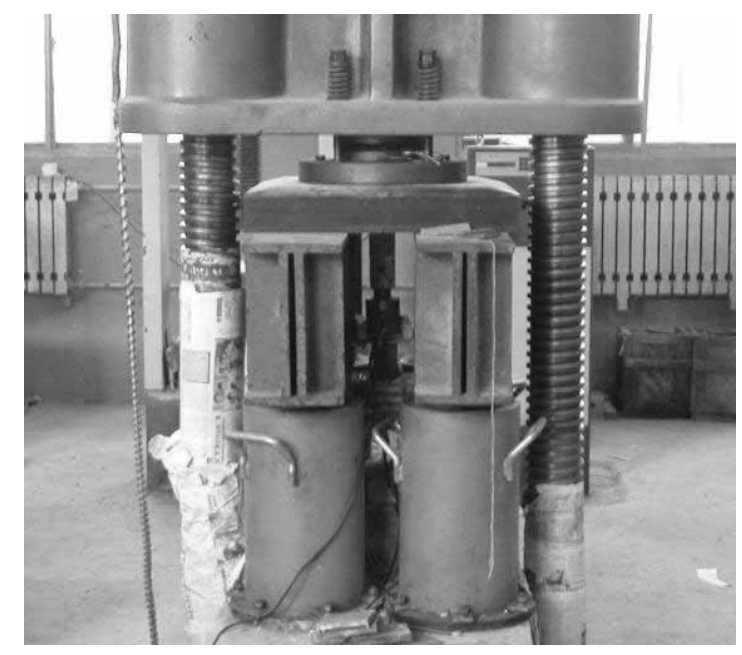

Figure 1. Loading device of three-point bending test

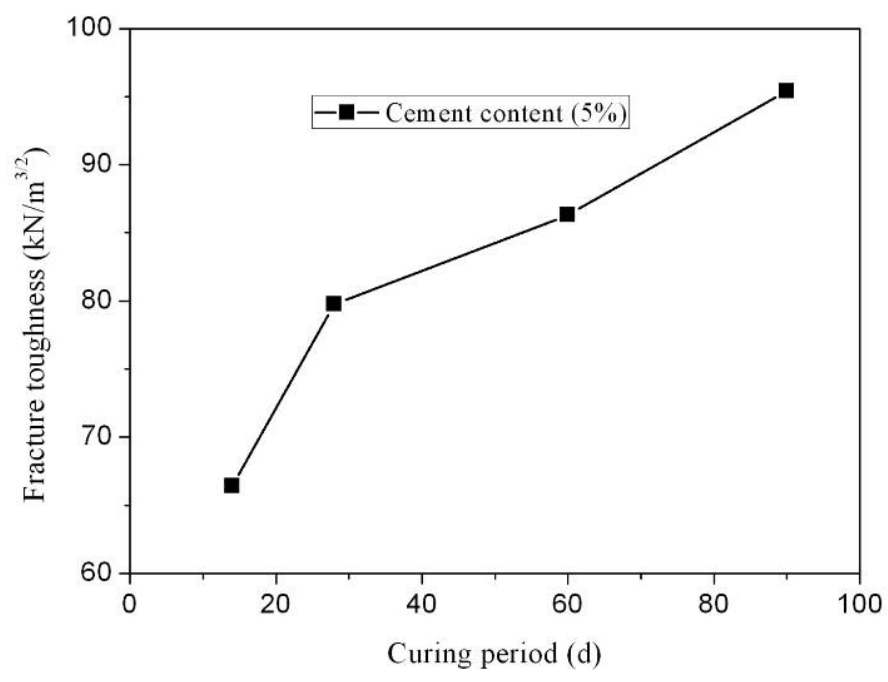

Figure 2. Effect of curing period on fracture toughness 


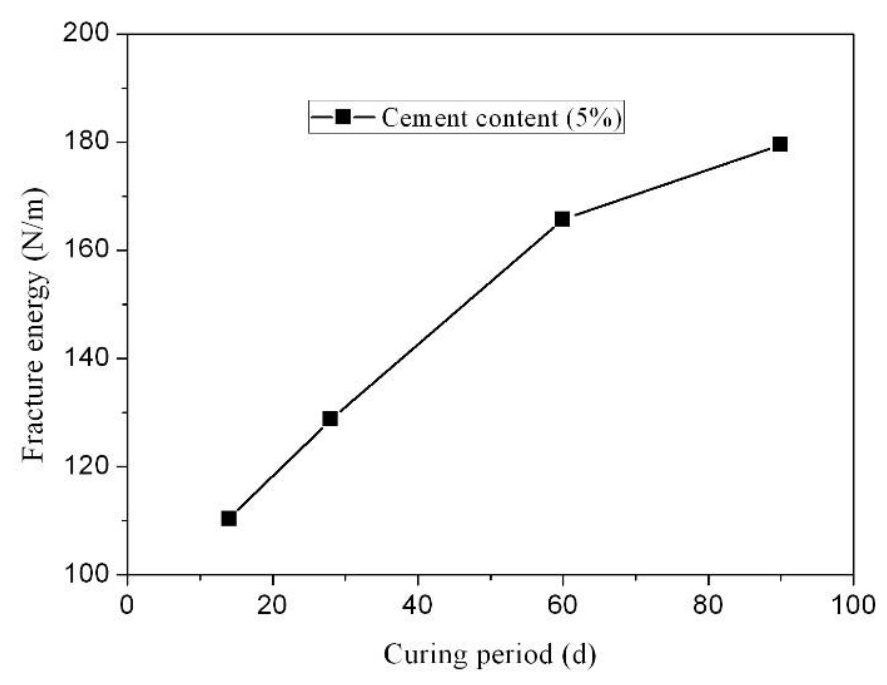

Figure 3. Effect of curing period on fracture energy

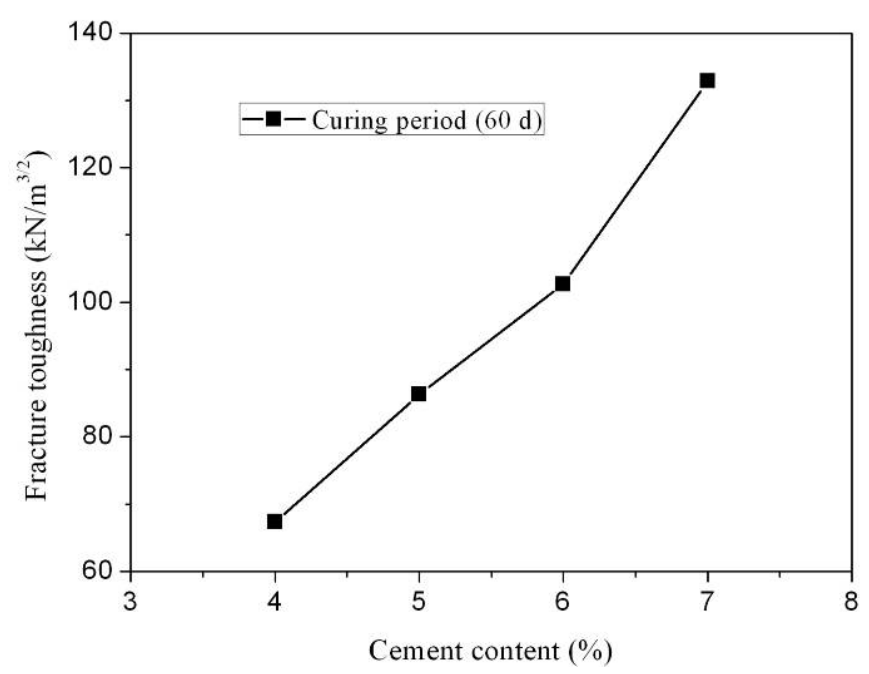

Figure 4. Effect of cement content on fracture toughness

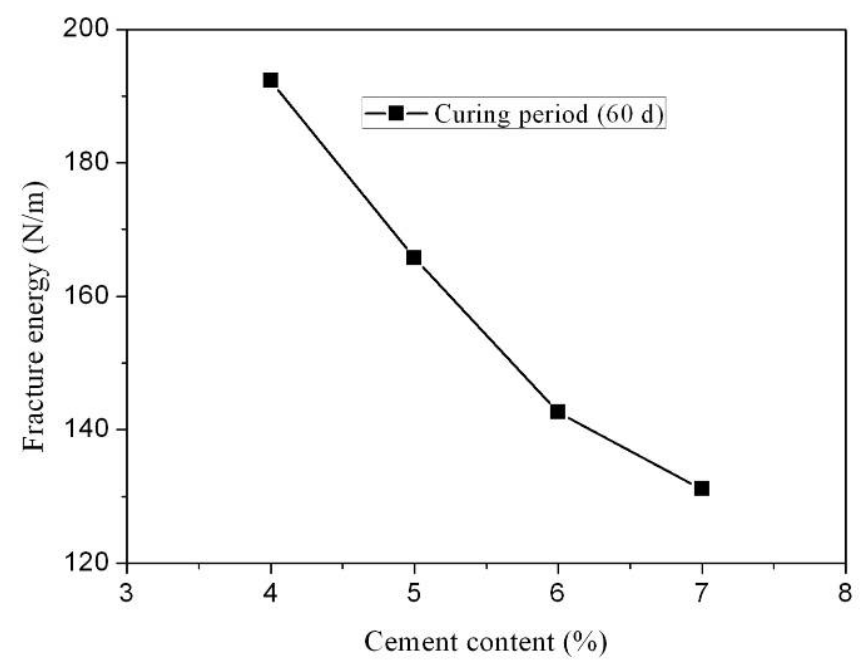

Figure 5. Effect of cement content on fracture energy 